\title{
Hybrid Thermal Modeling to Predict LED Thermal Behavior in Hybrid Electronics
}

\author{
Esa Hannila ${ }^{1}$, Noora Heinilehto, Kari Remes, Janne Lauri, Kimmo Keränen and Tapio Fabritius
}

\begin{abstract}
Hybrid structural electronics (HSE) consists of printed electronics, conventional rigid electronics and load bearing supporting parts of a device (plastic, glass etc.). Extra-large area and flexible lighting elements with embedded light emitting diodes (LEDs) are an example of such applications. LEDs can be used e.g. as light sources to create smart surfaces for the architectural or automotive industry. Once the LEDs are embedded into the structure, they cannot be replaced. In order to make sustainable HSE products with long lifetime, the new type of designs is needed. The elements of HSE undergoes conditions with elevated thermal stresses while in operation. That is known to have an impact on their performance and lifetime, thus making a proper heat management of the LED crucial. Due to the novel additive manufacturing methods, structures, and unconventional material combinations, many thermal management related aspects are not known. In this study, a two-step hybrid method, including thermal modelling and measurements, is utilized to estimate thermal behavior of a surface mounted LED on polymer substrate used in HSE. The model is created and simulated in COMSOL Multiphysics. The validity and accuracy of the model's thermal behavior is verified through measurements with thermal transient measurements. Based on the experimental verification, the proposed simulation model only has small (less than $2 \%$ ) temperature variations when compared with measurements. Hence, the developed model can be used as a basis for designing structural LED elements and predicting their performance characteristics in different user cases.
\end{abstract}

Keywords-printed electronics, hybrid electronics, model verification, junction temperature, lifetime.

\section{INTRODUCTION}

$\mathrm{O}$ ne emerging field of electronics is so called hybrid electronics (HE) where flexible printed electronics is combined with conventional silicon-based electronics. HE is exploiting the pros of both techniques. Printed electronics is exploited to acquire large area, lightweight, low-cost and flexibility while conventional electronics is used to attain high performance and reliability [1]-[3]. In addition, interest towards $\mathrm{HE}$ is increased because it enables embedding the electronics within the load bearing and protective structures, leading eventually to another concept, so called structural electronics (SE) [4], [5].

Smart glass laminates consisting of electronical functionalities embedded within the structure [6], [7], are practical examples of hybrid structural electronics (HSE) products exploited in architectural industry as enhancing,

This work is financially supported by Business Finland funded project (Dnro 3944/31/2014), Academy of Finland's FIRI funding (grant no. 320017) and European Regional Development Fund's Novel Digitally Fabricated Materials for Electronics, Optics and Medical Applications (grant no. A74080). decorative elements or as the protective windshields of vehicle in automotive industry [8]-[10]. In addition, different plastic integrated gadgets and user interfaces based on HSE have been reported recently [11]. For now, the main interest of the industry lies on different type of smart surfaces including e.g. dynamic features displays or Internet of Things (IoT) connectivity. Due to the nature of the SE, HSE intermediate products are merged inside the structure, restricting the replacement of components afterwards. Thus, the fabrication technique, materials, component, and the electrical and structural design must be selected carefully to obtain high quality and reliable structural electronics products.

Development for the printing techniques has led to multi material and hybrid 3D-printing. The techniques utilize multiple printing heads in one system to dispense various materials. Systems are often modular and can be equipped even with third party products such as cameras for machine vision or a pick-and-place module for electric components. The ability to print multiple materials and to assemble electronics in a single process flow has high potential to accelerate the innovation and the manufacturing. Single process flow to build a complete device, could also eliminate any human errors during the manufacturing. Multi material hybrid 3D-printing is very promising and could be used in manufacturing processes for both HE and SE due to its capabilities allowing the dispose of separate process steps and using components as embedded part of the structure, resulting in accelerated, high quality manufacturing for structural hybrid electronics. [12-13] For now, additive manufacturing is quite novel in the field of electronics and involves unknown factors. Material properties can variate between bulk and printed material, hence, affecting e.g. on the heat transfer through device structure. Some structural differences also exist when utilizing additive manufacturing methods, creating variations within sample populations, and affecting on the characteristics of $\mathrm{HE}$ or SE devices. [7]

Light-emitting devices (LEDs) based on conventional semiconductors, typically silicon, are often used as a light source in optoelectronics based smart surfaces. LEDs are favorable for structural hybrid electronics due to their great light emitting properties, low power requirements, small size, and long lifetime [14], [15]. Most of the LEDs are also comprehensively studied and well-understood in terms of functionality and reliability. The pn-junction temperature and driving current of LEDs are known to have major impact on their performance and lifetime [16], [17]. Since the luminosity

E. Hannila, K. Remes, J. Lauri, T. Fabritius, Optoelectronics and Measurement Techniques Research Unit, ITEE), University of Oulu, Erkki Koiso-Kanttilan katu 3, 90570 Oulu, (email: esa.hannila@oulu.fi)

N. Heinilehto, K.Keränen, VTT Technical Research Center of Finland Ltd, Kaitoväylä 1, 90570 Oulu 
of LED is current-dependent, reducing drive-current to lower the junction temperature of devices are not usually an option in $\mathrm{HE}$ and SE applications. Instead, a proper design for a heat transferring structure is necessary to lower the junction temperature.

In the case of SE, the LEDs undergo considerably high temperature cycles during the manufacturing process $[7,6]$. In addition, their operational conditions and interfaces inside the SE element are unconventional. Thermal management of the device by the utilization cooling elements such as heatsinks, may not be applicable since transparency is often required in HSE products. However, due to the characteristics of the SE, the device structure acts as cooling element for LEDs. The cooling effect of the SE device structure is not well known, nor are there knowledge or specific design rules to achieve sufficient temperature control. [7] Since the optimization of those properties, based on iterative experimental development is resource demanding, a quicker and more inexpensive modelling-based design is required.

There are publicly available articles about measurement or simulation-based evaluations for temperature distribution and thermal resistance of power LEDs. The existing articles provide broad background information about thermal modeling and different thermal management methods. However, simulationbased evaluations of $\mathrm{HE}$ and SE are mostly unexplored field of research. [18]-[25] The compact thermal modelling and simplifying complex circuits into RC ladder network described in [26-27] is a quick method to evaluate thermal characteristics of a device. In this study, we focused on single LED and its packaging, hence, we required a detailed 3D thermal model allowing more precise visualization of thermal conduction throughout the structure. A two-step hybrid method, utilizing thermal simulations and temperature measurements, is found to be reliable to predict the thermal behavior of a LED [24], [25], and is used in our research as well. The concept is used to effectively estimate the temperature distribution and thus, the lifetime of the LED with existing product reliability data. The method consists of 3D finite element modeling, which is based on the material properties and the structure, and accurate thermal measurement for calibration and verification of the model [24].

In our previous paper, we created the first version of a model for Luxeon 3014 LED to simulate its thermal behavior [28]. In this extended version the LED model is improved and the junction temperature of the LED samples with different powering currents are measured to verify the validity and accuracy of the model. In addition, the temperature behavior of
LED embedded in the 3D polymer structure is simulated to demonstrate the potential of the developed model for application specific case and the benefits of the SE concept regarding to heat transfer over HE devices.

\section{MATERIALS AND METHODS}

LEDs were assembled and attached to printed silver conductive wires and a flexible polyethylene terephthalate (PET) film using two adhesives. An identical model, a digital replica was created using COMSOL Multiphysics - simulation software. Performed measurements were utilized to evaluate and verify the simulation model.

\section{A. Specifications of the used materials}

The structures of the measured samples consist of screenprinted conductors on PET substrate with the thickness of 125 $\mu \mathrm{m}$. LS-411AW silver ink by Asahi was used for the screen printing of conductive wires. Luxeon 3014 LEDs were attached on the substrate and conductors with two types of adhesives. The first adhesive, an UV-curable supporting epoxy AA 3525 by Loctite was used to prevent the LED from getting detached from the substrate by mechanical stresses during and after the manufacturing. The second, conductive adhesive H20E by Epotek used to ensure a galvanic contact to the conductors. The materials used in the manufacturing process of the samples and their technical details are summarized in Table I.

\section{B. Layout of the sample}

The layout of the samples composes mainly from the printed conductive wire pattern, which is depicted in Fig. 1. In addition to the printed silver wires, the sample consists of $3 \times 1.4 \times 0.7$ $\mathrm{mm}$ LED components and a regulator to control fluctuations in supply voltage. The wire pattern is printed with two different linewidths. Most of the wire pattern was printed with larger linewidth but narrower lines are used as much as possible to maximize the transparency. Each component is connected in series within the narrower part of the printed wire pattern.

\section{Fabrication process of the samples}

The fabrication process for the measured samples consists of two main steps. In the first step, the conductive wires were rotary screen printed on the PET substrate in a roll-to-roll (R2R) process at the premises of VTT (Technical Research Centre of Finland, Oulu, Finland). After the conductors were printed, they were cured in temperature based post-processing for 2 minutes at $140{ }^{\circ} \mathrm{C}$. After the curing of the printed wires, LEDs and regulator were attached. Conductive adhesive was utilized to ensure the galvanic contact between the LED electrodes and the

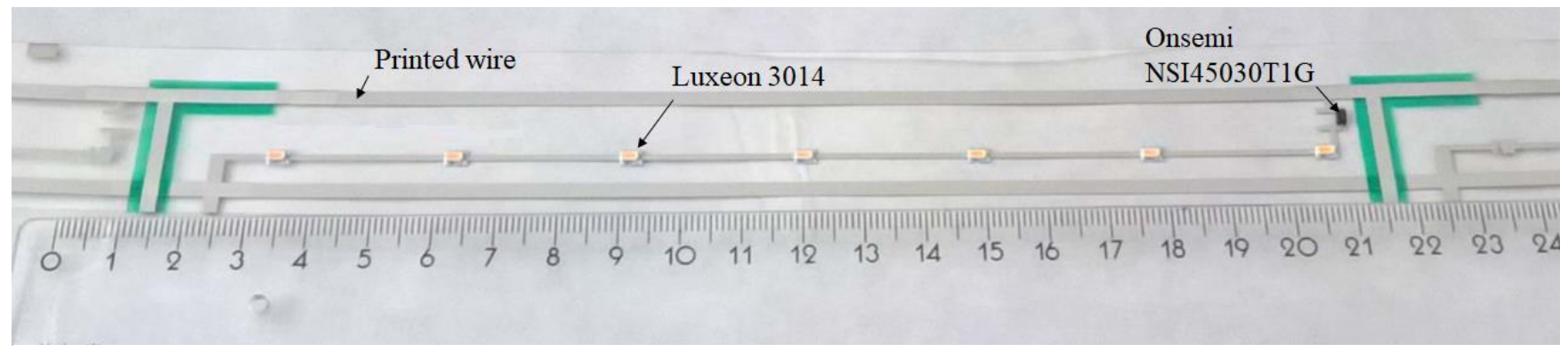

Fig. 1. Photograph of the sample measured with T3ster. The results are utilized in evaluation of the COMSOL simulation model. Sample's design consists of the printed conductive wire pattern and the multiple serially connected LEDs and the regulator. The surface mounted components are attached on the wire patterns and substrate using adhesives. One of the adhesives is utilized to maintain a galvanic contact to the conductors and the other is utilized to prevent components from detaching because of mechanical stresses. 
TABLE I

SPECIFICATIONS OF USED MATERIALS AND COMPONENTS

\begin{tabular}{|c|c|c|}
\hline Material/Component & Details & Comment \\
\hline Conductive adhesive & Epotek H20E & $\begin{array}{l}\text { Isotropically } \\
\text { conductive adhesive }\end{array}$ \\
\hline Conductive wires & Asahi LS-411AW & $\begin{array}{l}\text { Silver paste for } \\
\text { screen printing }\end{array}$ \\
\hline Film & PET & $\begin{array}{l}\text { Carrier film for } \\
\text { electronics }\end{array}$ \\
\hline LED & Luxeon 3014 & $\begin{array}{l}\text { Surface mounted } \\
\text { LED }\end{array}$ \\
\hline Regulator & $\begin{array}{l}\text { Onsemi } \\
\text { NSI45030T1G }\end{array}$ & $\begin{array}{l}\text { Surface mounted } \\
\text { regulator }\end{array}$ \\
\hline Support epoxy & Loctite AA 3525 & Supporting epoxy \\
\hline
\end{tabular}

printed wire. Since H20E breaks easily when subjected to a mechanical stress, supporting epoxy was utilized to reinforce the conductive bond and prevent the components from detaching the substrate and printed wires. Some samples were additionally embedded inside a polymer structure. Polymer structures were 3D-printed from polylactic acid (PLA) using a fused filament fabrication (FFF) 3D-printer in the premises of Fab Lab Oulu. Structures were printed in two pieces that formed a top and a bottom part. The side length of the printed structure was $10 \mathrm{~mm}$ and had the height of $1 \mathrm{~mm}$. The structure had a small section removed at two opposing sides leaving small part of the printed wires exposed and allowing galvanic contact to them. Sample was finished by sandwiching the LED system between the 3D-printed PLA pieces.

\section{T3ster measurements}

T3ster is a measurement device for thermal transient testing. It is utilized in characterization of thermal properties for digital ICs and semiconductors such as LEDs. The measurement process is based on a known constant current and a measured voltage to define thermal resistivity of a component or material. The measurement is divided in two main phases. In the first phase the K-factor of the sample is defined by leading a small sensing current, which does not result in heating, and the voltage drop over the component at certain temperature range is measured. The $\mathrm{K}$-factor is then obtained from the slope of the voltage-temperature curve. During the second phase of the measurement, the sample is heated using a higher powering current. After the temperature of the sample is saturated, the heating current is switched back to the sensing current. The voltage over the LED is measured while the sample cools down at ambient temperature. The voltage drop is converted to temperature change using the sensitivity value, which is reciprocal to the K-factor defined in the first phase. In this study T3ster was utilized to measure the thermal properties of the LED by measuring its junction temperature. [29], [30]

\section{E. Synchronized Thermography measurements}

Synchronized thermography (ST) is a characterization technique utilized e.g. in uniformity and electronics property analysis of printed and hybrid electronics. The technique is based on the utilization of synchronized infrared (IR) imaging and electrical heating. Error limits specified for the camera are $\pm 2{ }^{\circ} \mathrm{C}$ or $\pm 2 \%$, whichever is greater. An electrical uniformity analysis or determination of electrical defects for large area thin film electronics can be very challenging for any other methods. However, ST has proven to be a very effective tool to detect them and hence, it can be utilized to maintain a high process throughput yield and quality of output products for the manufacturing of printed electronics. [31]-[35]

In this study, an in-house made ST system was used to measure the surface temperature of 3D-printed PLA structure. The structure is heated by the LED embedded inside the structure. The results from the thermography measurements were used to verify the simulation model in the case where T3ster measurements are not feasible.

\section{F. Creating the simulation model}

A simulation model was created using COMSOL Multiphysics (version 5.3a by COMSOL Inc), which is a finite element analysis, solver, and Multiphysics simulation software. The heat transfer module of COMSOL was used solve the nonstationary heat transfer in the model structure for conduction, convection, and radiation according to assumptions in Eq. 1-3.

Heat conduction:

$$
\rho C_{P} \frac{\partial T}{\partial t}+\rho C_{P} u \cdot \nabla T+\nabla \cdot(-k \nabla T)=Q+Q_{t e d}
$$

Heat convection:

$$
-n q=q_{0}=h\left(T_{\text {ext }}-T\right)
$$

Horizontal boundary (upside)

$$
h=\left\{\begin{array}{l}
\frac{k}{L} 0.54 R a_{L}{ }^{1 / 4}, \text { if } T>T_{\text {ext }} \text { and } 10^{4} \leq R a_{L} \leq 10^{7} \\
\frac{k}{L} 0.15 R a_{L}{ }^{1 / 3}, \text { if } T>T_{\text {ext }} \text { and } 10^{7} \leq R a_{L} \leq 10^{11} \\
\frac{k}{L} 0.27 R a_{L}{ }^{1 / 4}, \text { if } T \leq T_{\text {ext }} \text { and } 10^{5} \leq R a_{L} \leq 10^{10}
\end{array}\right.
$$

Horizontal boundary (downside)

$$
h=\left\{\begin{array}{l}
\frac{k}{L} 0.54 R a_{L}{ }^{1 / 4}, \text { if } T \leq T_{\text {ext }} \text { and } 10^{4} \leq R a_{L} \leq 10^{7} \\
\frac{k}{L} 0.15 R a_{L}{ }^{1 / 3}, \text { if } T \leq T_{\text {ext }} \text { and } 10^{7} \leq R a_{L} \leq 10^{11} \\
\frac{k}{L} 0.27 R a_{L}{ }^{1 / 4}, \text { if } T>T_{\text {ext }} \text { and } 10^{5} \leq R a_{L} \leq 10^{10}
\end{array}\right.
$$

$h=\left\{\begin{array}{l}\frac{k}{L}\left(0.68+\frac{0.67 R a_{L}^{1 / 4}}{\left(1+\left(\frac{0.492 k}{\mu C_{p}}\right)^{9 / 16}\right)^{4 / 9}}\right), \text { if } R a_{L} \leq 10^{9} \\ \frac{k}{L}\left(0.825+\frac{0.387 R a_{L}^{1 / 6}}{\left(1+\left(\frac{0.492 k}{\mu C_{p}}\right)^{9 / 16}\right)^{8 / 27}}\right)^{2}, \text { if } R a_{L}>10^{9}\end{array}\right.$

Heat radiation

$$
-n q=\varepsilon \sigma\left(T_{a m b}^{4}-T^{4}\right)
$$

Initial temperature of the model and the ambient was set to 
room temperature. Measured values and the datasheet of the LED were utilized to design the geometry for the model (see Fig. 2.) Temperature distribution is assumed to be even throughout the LED chip due to its small size, thus, making it less dominant factor in terms of heat transfer for the whole geometry. In addition, details from the LED structure was not provided by the manufacturer, therefore, the model was simplified into $725 \times 280 \times 350 \mu \mathrm{m}$ chip consisting $\mathrm{p}$ - and $\mathrm{n}$-side semiconductor layers on top of substrate with an $50 \mu \mathrm{m}$ thick active region between them. Gallium nitride $(\mathrm{GaN})$ is chosen as semiconductor material due to the lighting and electrical characteristics of the LED. LED is attached to the $2 \mathrm{~mm}$ wide printed silver electrodes and $1 \mathrm{~mm}$ wide wires on top of the PET substrate with a conductive adhesive. Thickness of the printing pattern is $25 \mu \mathrm{m}$. Thermal model consists of GaN LED chip submerged in silicone encapsulation surrounded by a $2.9 \times 1.4 \times 0.7 \mathrm{~mm}$ Nylon 66 packaging. LED also has two copper electrodes connected to a LED chip with a golden wire bonding, overlapping the Nylon packaging and resulting into total length of $3 \mathrm{~mm}$. All the material parameters used in the simulation are presented in Table II. According to simulation results, the distance between adjacent LEDs is long enough to prevent them from affecting each other's temperature. Hence, only a single LED was simulated to keep the calculation time reasonable. Additionally, the regulator, which was removed during the T3ster measurements, was not simulated.

\section{G. Temperature simulation}

LED's temperature behaviour was simulated by setting a constant heating power over the domain of the active region of the LED structure. The amount of heating power depends on the corresponding forward current on each simulation case. LED's efficiency was measured during the study as 2pimeasurement inside integrating sphere using the forward current of $25 \mathrm{~mA}$. Expected uncertainty for integrated sphere and its sensor is given as a few percentages (minimum of \pm 1 $\%)$. Approximately $42.6 \%$ of the total electrical power is converted to the lighting power and the rest, $57.4 \%$, is

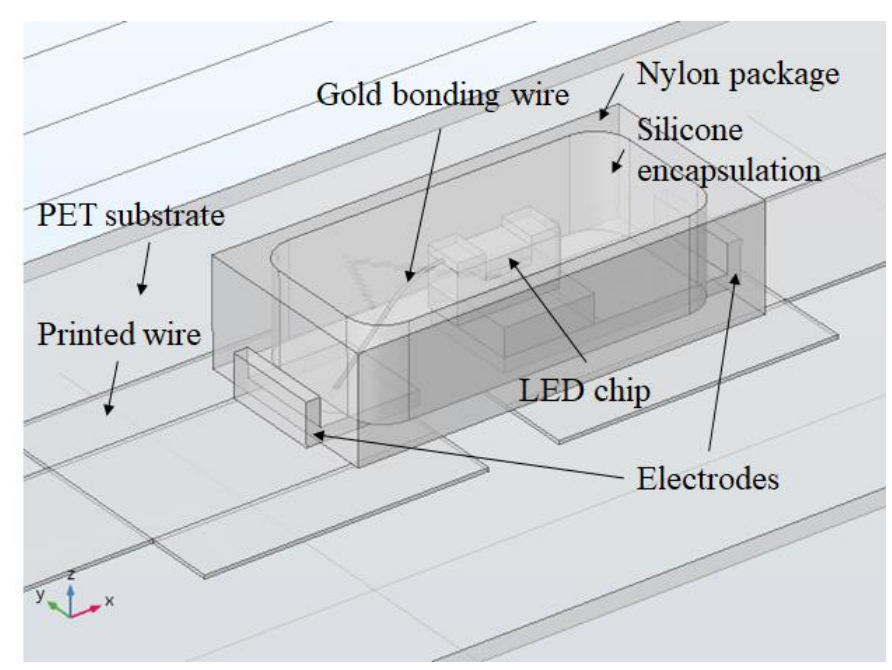

Fig. 2. LED simulation model's geometry designed in COMSOL Multiphysics -simulation software.

converted to the heating power. According to the datasheet of the LED provided by the manufacturer, the forward current of $25 \mathrm{~mA}$ over the LED corresponds to a forward voltage of 2.83 $\mathrm{V}$ resulting in a total electrical power of $70.8 \mathrm{~mW}$ and, in a total heating power of $40.6 \mathrm{~mW}$. However, at higher junction temperatures LED's efficiency starts to decrease according to its lighting output characteristics provided in the datasheet. Lighting output characteristics are normalized at $60 \mathrm{~mA}$ and 25 ${ }^{\circ} \mathrm{C}$ and the heating power is defined by subtracting the lighting power (see Eq. 4.) from total electrical power.

$$
\varphi_{\text {light }}=\left(\eta_{\text {current }} \times \eta_{\text {temp }}\right) \varphi_{\text {light } @ 60 m A}
$$

where $\varphi_{\text {light } @ 60 m A}$ is the lighting power at $60 \mathrm{~mA}$ forward current, $\eta_{\text {temp }}$ is temperature coefficient, $\eta_{\text {current }}$ is the current coefficient and $\varphi_{\text {light }}$ is the unknown lighting power. The simulations were done in two steps. In the first step, the junction temperature was simulated without taking the temperaturedependent efficiency loss into account. The second step utilizes the results from the first step to simulate the junction TABLE II

SPECIFICATIONS OF USED MATERIALS IN SIMULATION

\begin{tabular}{|c|c|c|c|c|c|c|c|}
\hline Component & Material & $\begin{array}{l}\text { Heat capacity at } \\
\text { constant pressure, } \\
\left(\mathrm{C}_{\mathrm{P}}\right)[\mathrm{J} /(\mathrm{KG} \cdot \mathrm{K})] \\
\end{array}$ & $\begin{array}{l}\text { Density, } \\
(\rho)\left[\mathrm{kg} / \mathrm{m}^{\wedge} 3\right]\end{array}$ & $\begin{array}{l}\text { Thermal conductivity, } \\
(\mathrm{k})[\mathrm{W} /(\mathrm{m} \cdot \mathrm{K})]\end{array}$ & $\begin{array}{l}\text { Electrical } \\
\text { conductivity }[\mathrm{S} / \mathrm{m}]\end{array}$ & $\begin{array}{l}\text { Relative } \\
\text { permittivity }\end{array}$ & $\begin{array}{l}\text { Surface } \\
\text { emissivity, }(\varepsilon)\end{array}$ \\
\hline Electrodes & Copper & 385 & 8960 & 400 & $5.998 \mathrm{e} 7$ & 1 (User) & 0.05 (User) \\
\hline Bonding wire & Gold, Au & 129 & 19300 & 317 & $45.6 \mathrm{e} 6$ & 6.9 (User) & - \\
\hline LED package & Nylon & 1700 & 1150 & 0.28 (User) & $1.0 \mathrm{e}-12$ (User) & 4 & 0.80 (User) \\
\hline Printed Wiring & Printed Silver & 245 (User) & 2650 (User) & 20 (User) & 2.5e6 (User) & 1 (User) & 0.05 (User) \\
\hline LED chip & $\mathrm{GaN}$ & 490 & 6150 & 130 (User) & $1.0 \mathrm{e}-18$ & 10.4 & - \\
\hline $\begin{array}{l}\text { LED } \\
\text { encapsulant }\end{array}$ & Silicone & Function* & Function* & 0.2 (User) & 1e-22 (User) & 4 (User) & 0.65 (User) \\
\hline $\begin{array}{l}\text { Conductive } \\
\text { adhesive }\end{array}$ & $\begin{array}{l}\text { Silver filled } \\
\text { epoxy }\end{array}$ & 787 (User) & 2670 (User) & Function* & $2.5 \mathrm{e} 5$ & 1 (User) & 0.15 (User) \\
\hline
\end{tabular}


temperature including the deterioration of LED's efficiency. Efficiency values for each simulation case are depicted in Table III.

Heating power and heat transferring methods (conduction, convection, and radiation) were defined depending on the simulation case and the orientation of the LED. Internal initial boundary conditions (BC) for heat conduction are defined automatically in the heat transfer module (Eq. 1). However, natural heat convection and radiation required separate heat flux and diffuse surface BCs included in the heat transfer module. Settings for heat flux can be modified to define the surrounding fluid, its temperature, and the orientation for specific boundary (e.g. horizontal or vertical). For horizontal boundary, it is also possible to define whether it is upside or downside. Heat transfer coefficient and heat transfer for natural convection is solved by COMSOL according to the BCs and initial assumptions (Eq. 2). Heat radiation was defined and solved similarly (Eq. 3) by setting up the ambient temperature, radiation direction and material-dependent surface emissivity in the diffuse surface BC. The simulated values for the junction temperatures were then compared with the measured temperature values to evaluate the model.

\section{RESULTS}

The LED samples were measured with T3ster thermal transient testing device, which allows measuring the junction temperature of a LED. Additionally, a thermal imaging system with synchronized heating was utilized to characterize the LED. Measurement results are utilized to verify the simulation model. The verified simulation model is used in COMSOL to evaluate the junction temperature of the LED for different user cases.

\section{A. T3ster measurements results}

T3ster was utilized to measure the junction temperature of the LED's active area. The accuracy of the device is given as $\pm 0.01^{\circ} \mathrm{C}$ and the sensitivity deviation within the sample population was $7.25 \pm 0.145 \mathrm{mV} / \mathrm{K}$. Measurements were done in two separate phases. At first, the junction temperature was measured while LEDs are arranged horizontally in air and heated with a forward heating currents of 25, 35, 45 and $60 \mathrm{~mA}$. After measuring the LEDs horizontally, they were measured vertically by repeating the same measurement process. The measurement results are presented in Table III. In the measurements, LED was heated until the junction temperature saturates $(2 \mathrm{~min})$. After the temperature of the LED was saturated, the heating current was switched to the sensing current and the LED was let to cool down while its temperature change was measured. As expected, the higher heating currents result into higher temperatures. However, according to the measurements results, the junction temperature is also affected by its orientation. The temperature of the LED is a bit higher when it is oriented horizontally in air compared to when it is oriented vertically. The horizontal temperature is approximately $1.6-7.7^{\circ} \mathrm{C}$ higher than vertical temperature.

The junction temperature of the LED samples was also measured in a plastic cover while being submerged into water bath at temperatures of 20,40 and $60{ }^{\circ} \mathrm{C}$ to evaluate the influence of a surrounding atmosphere on the heat conduction.
TABLE III

MEASURED RESULTS VS. SIMULATED RESULTS FOR AVERAGE JUNCTION TEMPERATURE

\begin{tabular}{llllll}
\hline \hline & & $\mathrm{T}\left({ }^{\circ} \mathrm{C}\right)$, & $\mathrm{T}\left({ }^{\circ} \mathrm{C}\right)$, & $\mathrm{T}\left({ }^{\circ} \mathrm{C}\right)$, & $\mathrm{T}\left({ }^{\circ} \mathrm{C}\right)$, \\
LED sample & Details & $\begin{array}{l}25 \mathrm{~mA}, \\
\eta \approx 0.43\end{array}$ & $\begin{array}{l}35 \mathrm{~mA}, \\
\eta \approx 0.48\end{array}$ & $\begin{array}{l}45 \mathrm{~mA}, \\
\eta \approx 0.34\end{array}$ & $\begin{array}{l}60 \mathrm{~mA}, \\
\eta \approx 0.22\end{array}$ \\
& & & & & \\
\hline Horizontal & Simulated & 69.0 & 91.9 & 118.0 & 169.6 \\
in air & Measured & 68.3 & 91.5 & 117.6 & 167.0 \\
Vertical in & Simulated & 66.4 & 88.7 & 113.5 & 161.0 \\
air & Measured. & 66.7 & 87.8 & 111.5 & 159.3 \\
& & & & & \\
\hline \hline
\end{tabular}

Sample was oriented horizontally in the water bath, and the heating current of $25 \mathrm{~mA}$ was used while its junction temperature was measured. The measurement results are presented in Table IV. This helped to extend possibilities to model the cases where LEDs are embedded inside structures relevant to $\mathrm{SE}$.

\section{B. Synchronized thermography results}

In addition to the T3ster measurements, synchronized thermography (ST) measurements were utilized to evaluate the temperature behaviour of the LED embedded as structural electronics inside the PLA structure and, to verify the existing model. In the ST measurements, the surface temperature of the PLA structure was measured instead of the active area of the LED. $25 \mathrm{~mA}$ forward current was driven through the LED as the heating current until the surface temperature of the PLA saturated. The sample was oriented horizontally during the measurement and the results are presented in Table IV. According to the results, it takes a rather long time, approximately 4 minutes for the surface temperature of the PLA to saturate.

\section{Simulation verification for T3ster}

In the first case, the junction temperatures were simulated in two parts. At first, the LED was simulated vertically in air after which it was simulat ed horizontally in air. The junction temperature was simulated using four separate values for heating power that are set as equivalent to forward current values of 25, 35, 45 and $60 \mathrm{~mA}$. The datasheet provided by the manufacturer was used to estimate the heating power for each current value. Both simulations parts were identical to each

TABLE IV

MEASURED RESULTS VS. SIMULATED RESULTS

\begin{tabular}{|c|c|c|}
\hline LED sample & Details & $\begin{array}{l}\mathrm{T}\left({ }^{\circ} \mathrm{C}\right), \\
25 \mathrm{~mA} \\
\eta \approx 0.44\end{array}$ \\
\hline $\begin{array}{l}\text { Average junction temperature } \\
\text { in water bath at } 20^{\circ} \mathrm{C}\end{array}$ & $\begin{array}{l}\text { Simulated } \\
\text { Measured }\end{array}$ & $\begin{array}{l}35.8 \\
34.9\end{array}$ \\
\hline $\begin{array}{l}\text { Average junction temperature } \\
\text { in water bath at } 40^{\circ} \mathrm{C}\end{array}$ & $\begin{array}{l}\text { Simulated } \\
\text { Measured }\end{array}$ & $\begin{array}{l}55.4 \\
54.0\end{array}$ \\
\hline $\begin{array}{l}\text { Average junction temperature } \\
\text { in water bath at } 60^{\circ} \mathrm{C}\end{array}$ & $\begin{array}{l}\text { Simulated } \\
\text { Measured }\end{array}$ & $\begin{array}{l}75.3 \\
74.1\end{array}$ \\
\hline $\begin{array}{l}\text { Max temperature of the PLA } \\
\text { structure (S1) }\end{array}$ & $\begin{array}{l}\text { Simulated } \\
\text { Measured }\end{array}$ & $\begin{array}{l}75.9 \\
74.7\end{array}$ \\
\hline $\begin{array}{l}\text { Max temperature of the PLA } \\
\text { structure with filling (S2) }\end{array}$ & Simulated & 54.5 \\
\hline
\end{tabular}


other with an exception of different orientation of the LED and the corresponding $\mathrm{BC}$ for the heat transfer mechanisms. In the simulation, the junction temperature of the LED was measured by a domain probe. The domain probe is a tool in COMSOL that allows the evaluation for average value of desired variable of selected domain or volume (in this case temperature of the active area). The simulation results are presented for vertical orientation in Fig. 3 and for both results in Table III. According to the simulation results, the junction temperature of the LED greatly depends on the forward current and it seems to rise exponentially within the current range. The orientation of the LED also seems to affect on its temperature in the simulations as well. While the LED is oriented horizontally the temperature values are approximately $2.6-8.6{ }^{\circ} \mathrm{C}$ higher compared to the vertical orientation of the LED.

In the second simulation case, the LED was protected by a $p$ lastic bag while being submerged to the water bath at temperatures of 20,40 and $60{ }^{\circ} \mathrm{C}$ and heated with the $25 \mathrm{~mA}$ forward current (see Fig. 4.). The simulation results are presented in Table IV. The junction temperature is now lower due to the improved heat transfer and it seems to rise linearly within the temperature range of water bath. However, at the higher water bath temperatures, the junction temperature is expected to rise exponentially due to the greater efficiency losses similarly to measurements in air.

\section{Simulation case for verified model}

A third simulation case was created to verify the existing LED model and to demonstrate its thermal behavior while being embedded inside the 3D printed plastic. The simulation model consists of the LED model embedded inside a PLA block, which is a common filament material used in $3 \mathrm{D}$ printing technology. There is an air gap between the PLA structure and LED, forming a thin insulating layer. Due to the insulating layer, a convective heat transfer is absent at the surface of the LED. The heating power and efficiency of the LED were defined as they were in the first two simulation cases by utilizing the datasheet provided by the manufacturer. The

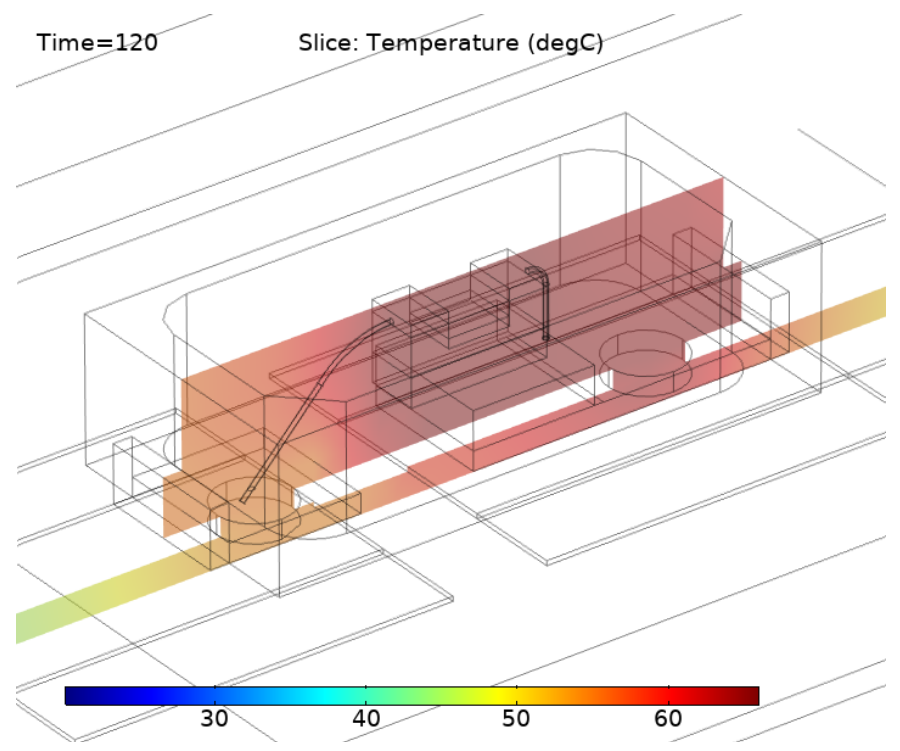

Fig. 3. Simulation results for the LED junction temperature when oriented vertically after 120 seconds of heating. The orientation of LED is set up in the boundary condition settings. maximum temperature for the surface of the PLA structure was measured with a boundary probe, which works similarly to the domain probe but for specific area and is defined to measure maximum temperature. The simulation results are presented in Figs. 5.-6 as well as in Table IV. According to results, the saturation time of the junction temperature is longer in both $\mathrm{S} 1$ and S2 structure when compared with results of LED in air. In addition, without any intermediate material between the LED and PLA (S1), the heat transfer deteriorates, and the temperature rises even higher than it did in air. However, the junction temperature could be lowered approximately $21.4{ }^{\circ} \mathrm{C}$ by filling the air gap with intermediate material e.g. with silicone (S2).

\section{DISCUSSIONS}

As in existing studies, we were able to utilize the hybrid prediction method to create a thermal model for fast and accurate evaluation of junction temperature in $\mathrm{HE}$ and $\mathrm{SE}$ applications. Since additive manufacturing is novel in the field of electronics, not only it involves manufacturing-related but also material-related inaccuracies affecting on the device properties. Printed material varies from corresponding bulk material causing changes in the operation of the device. However, we believe such variation can be considered in thermal modelling, thus making it feasible tool for designing modern-day electronics.

In the first simulation case, with each prescribed heating powers equivalent to the forward currents from 25 to $60 \mathrm{~mA}$ and, in the second simulation case, with the water bath temperatures from 20 to $60{ }^{\circ} \mathrm{C}$ using $25 \mathrm{~mA}$, the junction temperature of the LED saturates well before heating is stopped. The saturation time is not crucial for the simulation or the function of the LED, however, it is crucial for thermal transient measurements. According to the simulation results, the two-minute time given for the junction temperature to stabilize in the T3ster measurements is more than enough and the results should comparable and reliable.

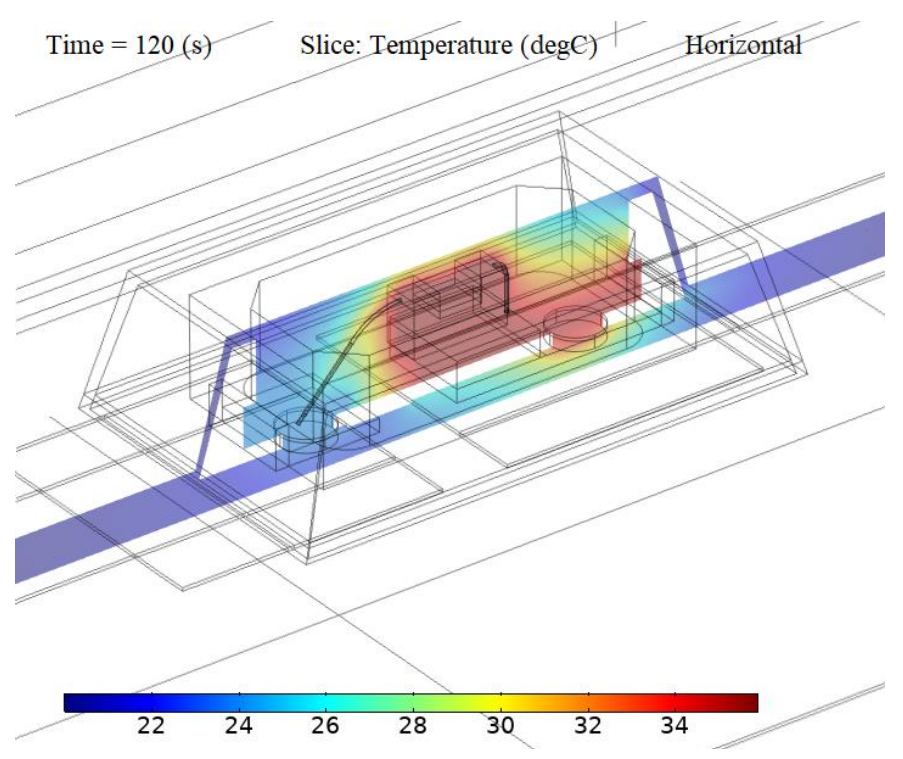

Fig. 4. Simulation results for the LED junction temperature when horizontally submerged under water bath. LED is protected with a plastic bag and small air gap between the LED and plastic is expected. 


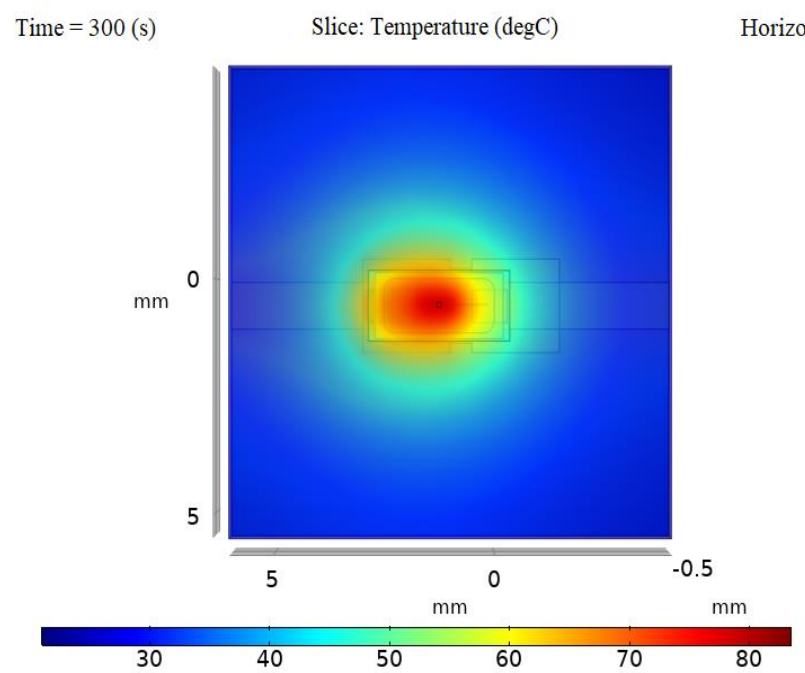

Fig. 5. Simulation results for the surface temperature of the 3D printed PLA structure heated by the LED. LED is embedded inside the PLA as structural electronics. Small air gap is expected between the LED and PLA structure as insulator and affects the junction temperature.

The highest temperature is located at the pn-junction of the LED as it should. Heat conducts through the structure to the surface of the LED packaging from which the heat transfer is both convective and radiative. The results from the simulation and the independently conducted measurements are almost identical thus verifying the accuracy of the proposed model. The simulated temperature values differ approximately 0.3 to $2.6{ }^{\circ} \mathrm{C}$ from the measured values when oriented both horizontally and vertically (See Table III). In both measured and simulated results, the junction temperature is higher when the LED is oriented horizontally than when it was oriented vertically suggesting an improved heat convection for the vertical orientation. That observation is good to keep in mind while more complex SE systems are designed.

LEDs were also measured in the water bath at the temperature range from 20 to $60^{\circ} \mathrm{C}$ with $20^{\circ} \mathrm{C}$ steps, hence, the second simulation case, using the same LED model, was created (Fig. 4.). Both the temperature of the active region and the heat transfer through the structure in the second simulation case match as well. According to the results (see Table IV.), the junction temperature of a LED could be lowered by submerging it into heat conductive materials (water bath in this case). Therefore, using the LED as an embedded element of the structure might be beneficial in terms of heat transfer. Improved heat transfer is inversely proportional to the junction temperature of the LED, which is known to have an influence on its lifetime [16]. Improved heat transfer and lower junction temperatures can be explained by the improved heat conduction, which replaces the heat convection. At $20^{\circ} \mathrm{C}$ water bath, the junction temperature is roughly $33{ }^{\circ} \mathrm{C}$ and at $40{ }^{\circ} \mathrm{C}$ water bath about $14{ }^{\circ} \mathrm{C}$ below the junction temperature measured in air at room temperature. Once the temperature of the water bath starts to converge the measured temperature results in air (water bath at $60{ }^{\circ} \mathrm{C}$ ) the junction temperature starts to rise above the junction temperature measured in first case. Similar results are acquired from the simulation and the variations between simulated and measured results for submerged LED are approximately $0.9-1.4{ }^{\circ} \mathrm{C}$ (See Table IV).

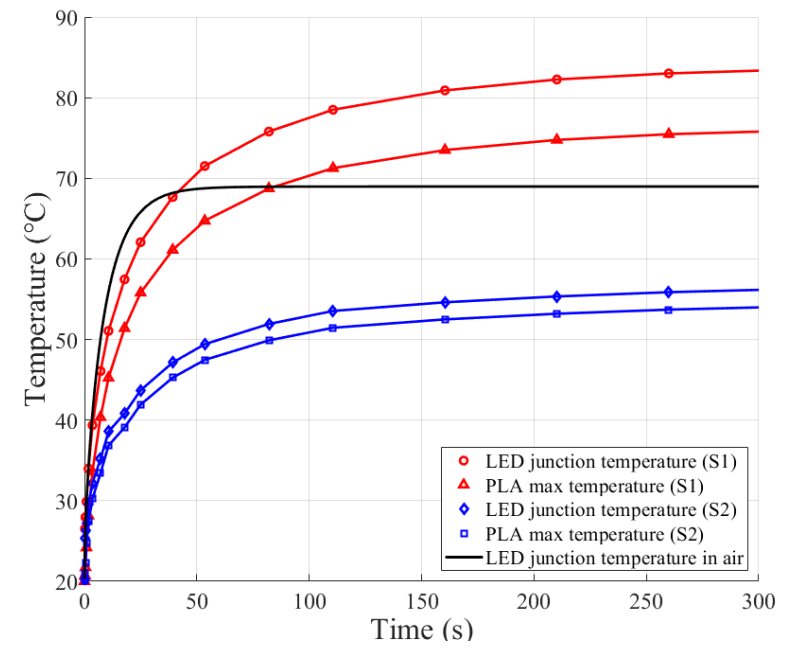

Fig. 6. LED's average junction temperature and the maximum temperature for outer PLA surface above the LED as a function of time. Temperature saturation is slower in PLA structure and it rises higher for S1 structure.

The T3ster is expected to cause only minor uncertainty to the model verification. The IR-based measurements are coherent, but the higher uncertainty of IR camera is limiting its precision for model verification. The small differences between the simulated and measured results for the junction temperatures can be partially explained by the geometry and material properties used in the simulation model. Some geometry related features were not created with an absolute accuracy since every detail from the structure of the LED is not available. The model's geometry is simplified version and involves some inaccuracies. Additionally, manufacturers may utilize material compounds with enhanced material properties such as thermal conductivity e.g. Nylon 66. Every detail for such material parameters may not be available or they might variate depending on the material manufacturer. Assumptions of those compounds may result in inaccurate material parameters. We assumed that the small variations in results due to the approximation of the model were within acceptable limits and the simulation to predict junction temperature with sufficient accuracy.

As the simulation model was found to be valid, a third measurement and simulation case was made to investigate thermal characteristics of the LED element inside the 3D printed plastic structure. Synchronized thermography measurement system was utilized instead of T3ster to measure the surface temperature of the structure. Variation between the simulation and measurement is approximately $1.2{ }^{\circ} \mathrm{C}$, which is within the specified uncertainty of the camera (Figs. 5.-6. and Table IV.). According to the results, the saturation time is rather long and the junction temperature of the LED rises higher than it did in air. The higher temperatures could be a consequence of an absent heat convection from the surface of the LED due to the insulating air gap between the LED and the PLA structure, leaving heat radiation as only heat transfer method from LED to PLA.

Heat transfer in PLA structure is conductive and, on the surface, convective and radiative. While the LED is powered, the surface temperature locally exceeds the glass transition temperature $\left(\mathrm{T}_{\mathrm{g}}\right)$, which for PLA is approximately $60{ }^{\circ} \mathrm{C}$. Exceeding the $T_{g}$ is problematic because at $T_{g}$ and higher 
temperatures, plastics will transit form rigid state to more flexible state affecting to its mechanical strength. Currently, the $\mathrm{T}_{\mathrm{g}}$ is exceeded even with the lowest operating conditions for the LED, emphasizing the importance of proper design rules and right material and component selection. According to simulations, the maximum temperature of PLA could be lowered below the $\mathrm{Tg}$ of PLA $\left(\sim 54.5^{\circ} \mathrm{C}\right)$ by filling the air gap e.g. with silicone. Thus, the concept of structural electronics seems to be beneficial in terms of heat transfer if proper structure design is achieved.

Another valid concerns for such structure, especially when intermediate material is used, would be mechanical strength and thermomechanical stresses. For now, evaluations for durability against external forces or thermomechanical stresses was discarded from the simulation since only the thermal properties of the structure was investigated. However, they might cause some problems for such supporting structures in which the LEDs are embedded in, causing for example delamination or irreversible deformations. It is worth to mention that simulations for thermal stress could be done with simple modification steps, but it will exponentially increase the simulation time.

\section{CONCLUSION}

The existing model is verified utilizing the hybrid thermal modelling at multiple points and has shown to be working accurately by independent measurements. The simulations and measurement results are almost identical and the heat transfer throughout the structure of the simulated model is reasonable. Therefore, it is possible to create a valid and reliable thermal model of a component and calibrate it with the aid of thermal measurements. Such model can be utilized to predict its thermal behavior in various environments. In other words, according to results, hybrid thermal modelling is a feasible and reliable method for predicting junction temperature of a LED in HE and SE applications. Results also suggest that embedding the HE element, i.e. concept of SE, can be beneficial in terms of heat transfer when designed properly. An accurate model enables fast and low-cost means to evaluate the component's thermal properties for many user cases. The results of the study indicate that a designer of $\mathrm{HE}$ or SE can utilize the hybrid thermal modeling when optimizing the structure design, component, and materials choice to improve thermal management. Because the lifetimes and functionality of a component is often temperature dependent, a model could be utilized in conjunction with manufacturer's reliability data for evaluation of reliability related aspects, thus enabling the product lifetime analysis.

\section{REFERENCES}

[1] G. Tong, Z. Jia and J. Chang, "Flexible Hybrid Electronics: Review and Challenges," in Proceedings IEEE International Symposium on Circuits and Systems, Florence, 2018.

[2] Y. Khan, M. Garg, Q. Gui, M. Schadt, A. Gaikwad, D. Han, N. Yamamoto, P. Hart, R. Welte, W. Wilson, S. Czarnecki, M. Poliks, Z. Jin, K. Ghose, F. Egitto, J.
Turner and A. Arias, "Flexible Hybrid Electronics: Direct Interfacing of Soft and Hard Electronics for Wearable Health Monitoring," Advanced Functional Materials, vol. 26, no. 47, pp. 8764-8775, 2016.

[3] K. Remes and T. Fabritius, "Non-contact Characterization of Flexible Hybrid Electronics by Synchronized Thermography," IEEE Transactions on Instrumentation and Measurement, no. DOI: 10.1109/TIM.2019.2962576, 2019.

[4] E. MacDonald, R. Salas, D. Espalin, M. Perez, E. Aguilera, D. Muse and R. Wicker, "3D printing for the rapid prototyping of structural electronics," IEEE Access, vol. 2, pp. 234-242, 2014.

[5] A. Lopes, E. MacDonald and R. Wicker, "Integrating stereolithography and direct print technologies for 3D structural electronics fabrication," Rapid Prototyping Journal, vol. 18, no. 2, pp. 129-143, 2012.

[6] J. Lauri, E. Hannila and T. Fabritius, "Non-destructive characterization of glass laminated electronics," in Conference Record - IEEE Instrumentation and Measurement Technology Conference, Auckland, 2019.

[7] E. Hannila, B. Augustine, T. Kurkela, J. Lauri and T. Fabritius, "Yield and Electrical Functionality of the Glass Laminated Conductive Wires and Connectors," IEEE Transactions on Components, Packaging and Manufacturing Technology, vol. doi: 10.1109/TCPMT.2019.2923858.

[8] J. Xu, Y. Li, B. Liu, M. Zhu and D. Ge, "Experimental study on mechanical behavior of PVB laminated glass under quasi-static and dynamic loadings," Composites Part B: Engineering, vol. 42 , no. 2, pp. 302-308, 2011.

[9] A. Berenjian and G. Whittleston, "History and Manufacturing of Glass," Americal Journal of Material Science, vol. 7, no. 1, pp. 18-24, 2017.

[10] A. Vedrtnam and S. Pawar, "Laminated plate theories and fracture of laminated glass plate - A review," Engineering Fracture Mechanics, vol. 186, pp. 316-330, 2017.

[11] T. Kololuoma, M. Keranen, T. Kurkela, T. Happonen, M. Korkalainen, M. Kehusmaa, L. Gomes, A. Branco, S. Ihme, C. Pinheiro, I. Kaisto, A. Colley and K. Ronka, "Adopting Hybrid Integrated Flexible Electronics in Products: Case - Personal Activity Meter," IEEE Journal of the Electron Devices Society, vol. 7, pp. 761768, 2019.

[12] P. Sitthi-Amorn, J. Ramos, Y. Wang, J. Kwan, J. Lan, W. Wang and W. Matusik, "MultiFab: A machine vision assisted platform for multi-material 3D printing," $A C M$ Transactions on Graphics, vol. 34, no. 4, 2015.

[13] A. Valentine, T. Busbee, J. Boley, J. Raney, A. Chortos, A. Kotikian, J. Berrigan, M. Durstock and J. Lewis, "Hybrid 3D Printing of Soft Electronics," Advanced Materials, vol. 29, no. 40, p. No. 1703817, 2017.

[14] M. Raypah, M. Devarajan and F. Sulaiman, "Effects of Substrate on Thermal and Optical Characteristics of High-Power ThinGaN White LED," IOP Conference 
Series: Materials Science and Engineering, vol. 409, no. $1,2018$.

[15] T. Cheng, X. Luo, S. Huang and S. Liu, "Thermal analysis and optimization of multiple LED packaging based on a general analytical solution," International Journal of Thermal Sciences, vol. 49, no. 1, pp. 196201, 2010.

[16] Lumileds, "WP15 Evaluating the Lifetime Behavior of LED Systems White Paper 20161201," Lumileds, 1 December 2016. [Online]. Available: https://www.lumileds.com/uploads/167/WP15-pdf. [Accessed 20 September 2019].

[17] H. Tang, D. Yang, G. Zhang, F. Hou, M. Cai and Z. Cui, "Multi-physics simulation and reliability analysis for LED luminaires under step stress accelerated degradation test," in 13th International Thermal, Mechanical and Multi-Physics Simulation and Experiments in Microelectronics and Microsystems, EuroSimE 2012, Cascais, 2012.

[18] O. Tapaninen, J. Ollila, E. Juntunen and K. Keränen, "Thermal management in flexible substrates for LEDs," in IMAPS Nordic Annual Conference Proceedings, Oulu, 2014.

[19] H.-K. Fu, C.-P. Wang, H.-C. Chiang, T.-T. Chen, C.-L. Chen and P.-T. Chou, "Evaluation of temperature distribution of LED module," Microelectronics Reliability, vol. 53, no. 4, pp. 554-559, 2013.

[20] E. Juntunen, A. Sitomaniemi, O. Tapaninen, R. Persons, M. Challingsworth and V. Heikkinen, "Thermal performance comparison of thick-film insulated aluminum substrates with metal core $\mathrm{PCBs}$ for highpower LED modules," IEEE Transactions on Components, Packaging and Manufacturing Technology, vol. 2, no. 12, pp. 1957-1964, 2012.

[21] J. Li, Q. Yang, P. Niu, L. Jin, B. Meng, Y. Li, Z. Xiao and X. Zhang, "Analysis of Thermal Field on Integrated LED Light Source Based on COMSOL Multi-physics Finite Element Simulation," in 1st International Conference on Physics Science and Technology, Hong Kong, 2011.

[22] B. Ramos-Alvarado, B. Feng and G. Peterson, "Comparison and optimization of single-phase liquid cooling devices for the heat dissipation of high-power LED arrays," Applied Thermal Engineering, vol. 59, no. 1-2, pp. 648-659, 2013.

[23] H. Ye, S. Koh, C. Yuan, H. Van Zeijl, A. Gielen, S.-W. Lee and G. Zhang, "Electrical-thermal-luminouschromatic model of phosphor-converted white lightemitting diodes," Applied Thermal Engineering, vol. 63, no. 2, pp. 588-597, 2014.

[24] M. Cai, D. Yang, K. Tian, W. Chen, X. Chen, P. Zhang, X. Fan and G. Zhang, "A hybrid prediction method on luminous flux maintenance of high-power LED lamps," Applied Thermal Engineering, vol. 95, pp. 482-490, 2016.
[25] M. Cai, Z. Liang, K.-M. Tian, M.-H. Yun, P. Zhang, D.G. Yang and G.-Q. Zhang, "Junction Temperature Prediction for LED Luminaires Based on a SubsystemSeparated Thermal Modeling Method," IEEE Access, vol. 7, pp. 119755-119764, 2019.

[26] A. Poppe, "Simulation of LED based luminaires by using multi-domain compact models of LEDs and compact thermal models of their thermal environment," Microelectronics Reliability, vol. 72, pp. 65-74, 2017.

[27] M. Janicki, P. Ptak, T. Torzewicz and K. Górecki, "Compact thermal modeling of modules containing multiple power LEDs," Energies, vol. 13, no. 12, p. No. 3130, 2020.

[28] E. Hannila, N. Heinilehto, J. Lauri, K. Keranen and T. Fabritius, "Measuring and modelling the thermal behaviour of LEDs in structural electronics," in I2MTC conference, 2020.

[29] Lumileds, "WP23 How to Measure Thermal Resistance of LED Emitters and LED Arrays White Paper 20161201," Lumileds, 1 December 2016 . [Online]. Available: https://www.lumileds.com/uploads/568/WP23-pdf. [Accessed 20 September 2019].

[30] J. Hu, L. Yang, W. Hwang and M. Shin, "Thermal and mechanical analysis of delamination in GaN-based lightemitting diode packages," Journal of Crystal Growth, vol. 288, no. 1, pp. 157-161, 2006.

[31] K. Leppänen, J. Saarela and T. Fabritius, "IR-imaging based system for detecting the defects of conductive materials," Proceedings of SPIE - The International Society for Optical Engineering, vol. 9205, p. no. 92050M, 2014.

[32] K. Remes, A. Järvenpää and T. Fabritius, "Contactless online characterization of large-area conductive thin films by thermography and induction," Optics Letters, vol. 44, no. 10, pp. 2574-2577, 2019.

[33] C. Schuss, K. Remes, K. Leppanen, J. Saarela, T. Fabritius, B. Eichberger and T. Rahkonen, "Detecting Defects in Photovoltaic Panels With the Help of Synchronized Thermography," IEEE Transactions on Instrumentation and Measurement, vol. 67, no. 5, pp. 1178 - 1186, 2018.

[34] K. Leppänen, J. Saarela, R. Myllylä and T. Fabritius, "Electrical heating synchronized with IR imaging to determine thin film defects," Optics Express, vol. 21, no. 26, pp. 32358-32370, 2013. DOI: 10.1364/OE.21.032358.

[35] K. Remes, K. Leppänen and T. Fabritius, "Thermography based online characterization of conductive thin films in large-scale electronics fabrication," Optics Express, vol. 26, no. 2, pp. 12191229, 2018. DOI: 10.1364/OE.26.001219. 


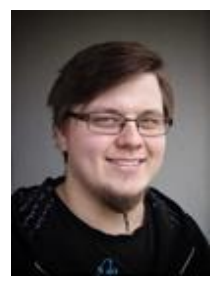

Esa Hannila received the M. Sc. degree and Doctoral study rights from University of Oulu, Oulu, Finland, in 2018. He has started working in the University of Oulu in 2017. He currently works in the research unit of Optoelectronics and Measurement Techniques as post-doctoral student. His current research interests involve reliability testing, Multiphysics simulations and development for printed intelligence and additive manufacturing methods.

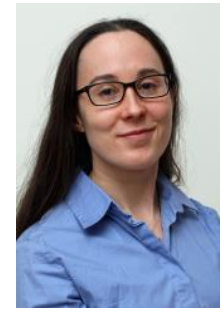

Noora Heinilehto joined VTT as a research scientist in June 2011. She received her M.Sc. (Tech.) degree in 2011 from the University of Oulu. Her major subject was in electrical engineering, specializing in microsystems engineering and applied electronics. Her master thesis and previous work in the Microelectronics and material physics laboratories in University of Oulu was focusing on basic research and material science. Currently, she works in the Photonics and RF Integration team at VTT. Her research projects have been concentrating on high precision packaging and assembly, including optical fibre packaging and waveguide characterization. She has participated in several EU and customer projects.

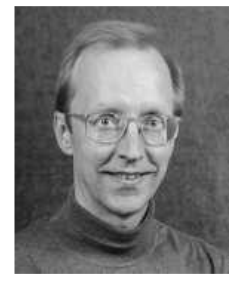

Kari Remes received the M.Sc. degree from the University of Oulu, Oulu, Finland, in 1991. Since 1992, he has been holding several research and development positions at different units of the University of Oulu, where he is currently a Project Manager with the Optoelectronics and Measurement Techniques Research Unit. His current research interests include online-compatible measurement and characterization techniques - especially thermography based - applied to printed electronics.

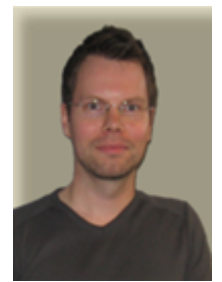

Janne Lauri is a post-doctoral researcher at the Optoelectronics and Measurement Techniques unit at the University of Oulu, Finland. He received the M.Sc. and D.Sc. (Tech.) degrees in engineering from the University of Oulu in 2007 and 2013, respectively. His research interests include optical coherence tomography, microfluidics, flow dynamics of industrial suspensions and development of optical imaging methods for printed intelligence manufacturing.

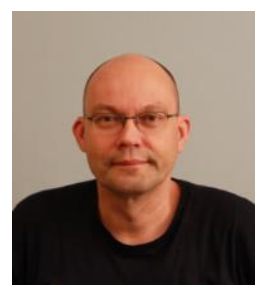

Kimmo Keränen received his MSc, Lic. Sc. and D. Sc (Tech.) degrees in electrical engineering from University of Oulu, Finland in 1992, 2002 and 2008, respectively. He is a Senior Scientist in Flexible Electronics Integration at VTT. His current research interests are in the field of photonic module and system integration based on flexible substrates. He is especially interested in building up versatile functionalities on flexible substrates utilizing semiconductor devices/components and hybrid integration technologies. Specific application area is large area lighting/display systems based on printed plastic substrates equipped with LEDs a in roll-to-roll manufacturing. He is author and co-author of over 20 journal papers and over 30 conference papers. He is a deputy board member of Photonics Finland and member of European Optical Society.

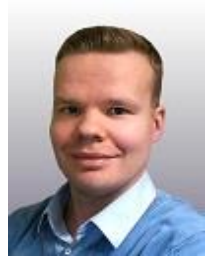

Tapio Fabritius received the M.Sc. and D.Sc. degrees (applied electronics) engineering from the University of Oulu, Oulu, Finland, in 2003 and 2007, respectively.

He has been with the University of Oulu since 2003, where he is currently a full Professor and the head of the Optoelectronics and Measurement Techniques Research Unit. His current research interests include the development of instrumentation and printed intelligence manufacturing technologies. He has published more than 65 peer-reviewed papers in reputed journals. 